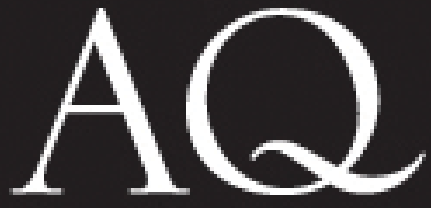

ANTHROPOLOGICAL QUARTERLY
IN THIS ISSUE:

The Dressman's Line: Transforming the Work of Costumers in Popular Hindi Film by Clare M. Wikkinson-Weber

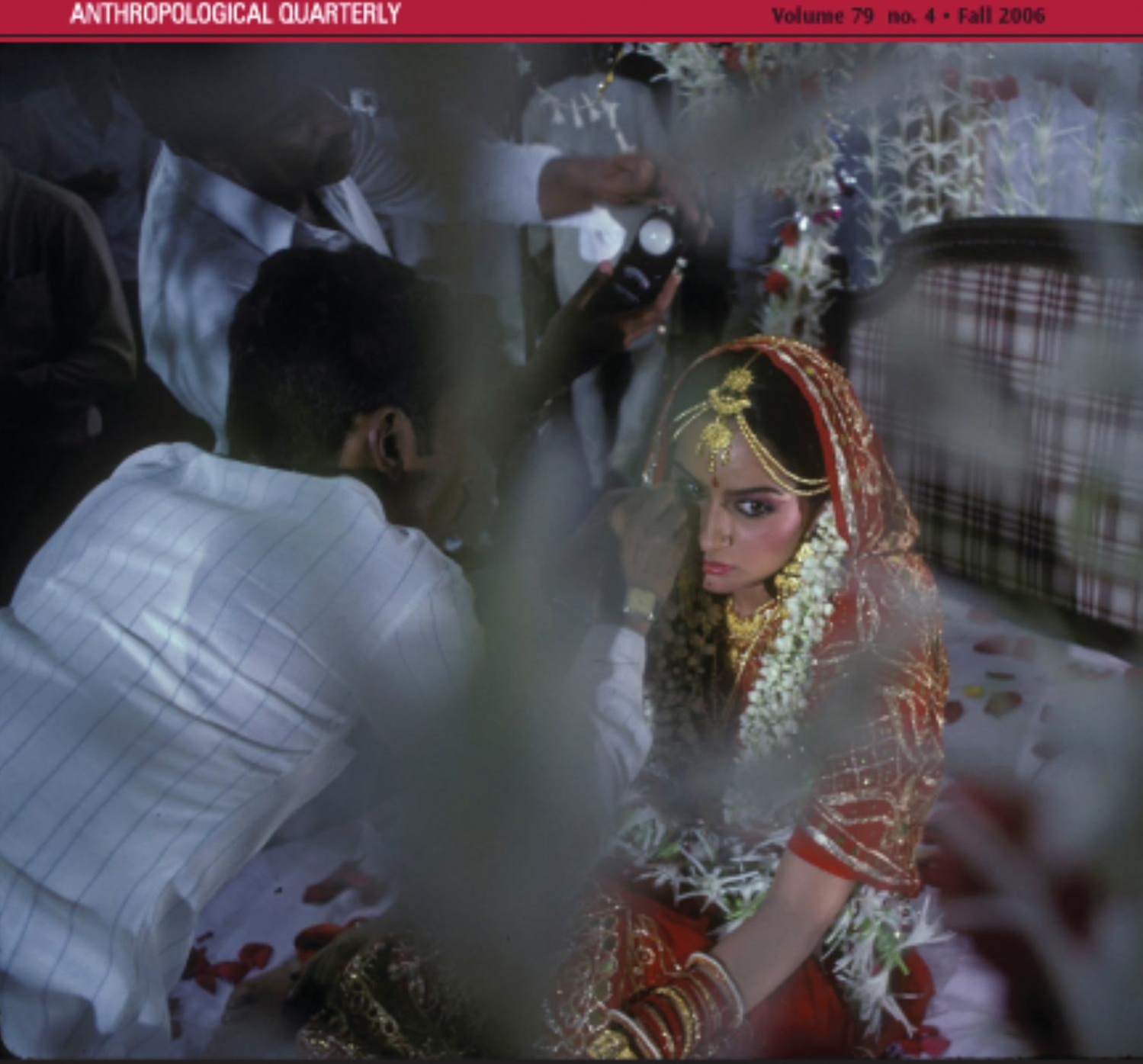

ALSO:

- A Mean-Spirited Sport: Japanese Brazilian Croquet in Săo Paulo's Public Spaces by Joshua Roth

- Can't Beat Me Own Drum in Me Own Native Land: Calypso Music and Tourism in the Panamanian Atlantic Coast by Carla Guerrón Montero

- Inter-area Ethnography: A Latin Americanist in Japan by Michelle Bigenho 



\title{
The Dressman's Line: Transforming the Work of Costumers in Popular Hindi Film
}

\author{
Clare M. Wilkinson-Weber \\ Washington State University-Vancouver
}

\begin{abstract}
Costumes in Hindi cinema are traditionally cared for on set by workers known as dressmen. Dressmen have always employed informal methods and techniques in their work, and they now find their skills, knowledge, as well as their privilege of maleness in a male-dominated industry being eroded as Hindi filmmaking is transforming itself aesthetically and organizationally in response to global forces. Interviews with dressmen with careers spanning nearly fifty years form the basis of a description of dressmen's discourses and practices. Dressman practices, in particular, are revealed to contribute in important ways to the appearance and meaning of costume in film. De-skilling of the dressman's job coincides with new organizational structures and the entry of assistant directors, many of them female, who claim superior knowledge of filmmaking techniques and of the fashion world that informs film costume. Studying film workers like dressmen informs our understanding of urban skilled workers in the Indian context, and provides a corrective to the exclusively semiotic approach to costume analysis that has prevailed to date. [Keywords: Film, globalization, India, work, Hindi cinema, costume]
\end{abstract}




\section{Introduction}

Of all the pleasures associated with watching popular Hindi films, viewing costumes is among the most obvious and influential. Semiotic analyses of Hindi film costume forms a small, but growing part of the scholarly literature on "Bollywood," (Kabir 2001:95; Dwyer and Patel 2002:81-100; Virdi 2003:2; Wilkinson-Weber 2005), and nicely complements important comparative texts examining the visual language of costume in American and European cinema (Gaines and Herzog 1990; Bruzzi 1997; Street 2001; Moseley 2005). The connection between costume and consumer practices has also been studied (Stacey 1994; Liechty 2002; Wilkinson-Weber 2005), reminding us that while costumes are the stuff of fantasy, they exert a strong influence in the world beyond film. Less often noted is how costumes issue from a world of work, and the social lives and relations of workers who make, buy, and take care of them. Costume production in Hindi film is embedded in a social world of independent tailors and menswear shops, designers, stylists, and theatrical supply shops. Positioned between set and source are workers known as "dressmen," who take care of film costumes. These social facts are intimately connected to how costume appears and "works" in Hindi films. In this paper, I argue that changes in the demands of the dressman's job, or "line," as it is termed in the industry, offer another way of understanding how and why films look the way they do. In addition, the dressman's story illustrates how transformation in the industry's organization and systems of control has affected the nature of skill and the value of knowledge among its workers.

Hindi films are the best known of India's cinematic output around the world. Despite accounting for only a fifth of the total of around 1,000 films made in India per year, Hindi films made in Mumbai far outweigh those made elsewhere in their appeal to a national, as well as an international audience (Dwyer and Patel 2002:8; Ganti 2004:3). Commercial Hindi films are arguably at their peak of global popularity, avidly consumed by Indian and non-Indian filmgoers in Africa, Asia, Europe, and the Americas. Filmmaking in India has a long history in India, going back over one hundred years. In the past fifteen years, though, there has been a notable shift in film subjects and production values coincident with the liberalization of the Indian economy (read: intensification of capitalism) (e.g. Chatterjee 2003; Virdi 2003; Ganti 2004; Ciecko 2006). Burgeoning fashion markets in large cities like Mumbai provide an ever larger supply of film costumes, meaning that film stars look substantially different from their antecedents. At the same time, film elites (including producers, directors and some actors) argue that the time is ripe for a more efficient, 
professional industry, and innovations in work styles are being affected. Women, previously confined to a few jobs in filmmaking including acting, dress designing, and hairdressing, are finding work on set as assistant directors. Changes in genre, characters, and production values are being matched, in other words, by shifts in power and personnel on set.

Little has been written about the actual production of films (but see Grimaud 2003; Ganti 2004), or the lives and work of technicians and craftspeople in the filmmaking industry (see Gangar 1995; Sengupta 2005). My own research is an attempt at redress, exploring the implications of change for more lowly film workers-in this case, costume workers. I met and interviewed dressmen both at film sets and away from them, in the course of ethnographic fieldwork in Mumbai aimed at documenting the work and opinions of personnel involved in all aspects of costume production: designers, tailors, embroiderers, costume supply shops, and wardrobe specialists. ${ }^{1}$ Dressmen in the Mumbai film industry today find themselves in a difficult position: they are part of an old guard of manual workers, accustomed to a virtually all-male industry where class and age were the salient social characteristics, whose particular skills and knowledge are of reduced importance in an industry that is now incorporating more upper class females, and is promoting new business practices, high technology, and the ideals and aesthetics of the upper middle classes.

Prasad (1998:49) has noted the periodic efforts of some Mumbai filmmakers, as "would-be agents of a bourgeois revolution," to "impose order on the industry's functioning, to regulate the work schedules of stars, to co-operate in reducing the duplications of themes" (31). In large part, these goals have remained elusive; but with the economic liberalization of the last 15 years, inroads can be, and have been, made into the production process of films: there is, for example, the influx of financing, strengthened yet flexible ties to settings outside India where filmmaking skills and conventions can be acquired, and improved technical aids to filmmaking (Dwyer and Patel 2002:26-28; Chatterjee 2003: 117 Ganti 2004:74, 88-90; Jain 2006:10). On this material foundation, a business discourse in the industry is linked with a broader discourse on professionalism and taste that sharply sets apart contemporary Bollywood from its past-a past that is embodied by workers who do not fit easily within this rhetoric.

As the commercial industry attempts to rationalize practices, the forms of knowledge that are valued within the industry are changing. De-skilling, or the reduction of skill in any given job as its component tasks are extracted 
and sorted into new divisions of labor, is a well-known component of the intervention of capital into labor processes (Marx 1977:462, Zuboff 1988:23). Stuart Marglin (1990:236) has sought to extend understanding of this process through a guided contrast of the terms episteme and techne. Marglin uses the contrast these terms represent and applies them to the transformations in the nature of work under capitalism: episteme, or knowledge acquired and deployed abstractly, accessible to a relative few, comes to replace techne, or practical and experience-based knowledge that exists within, and informs actual practices as industrial processes become more subject to the control of management. Marglin discusses these ideas in the Indian context, but specifically with reference to handicraft artisans-who, it is important to note- -he feels are somewhat immune to this transformation. In arguing for the usefulness of Marglin's contrast for understanding the case of dressmen, my point is that artisanal skills are at once more broadly based in India, and in some cases, quite as vulnerable to capitalist intervention as "craft" was in 19th century Europe. As elites in the film industry are struggling to develop an epistemic base for occupational specialization in the industry, their effort runs counter to the interests of workers whose skills reside in the world of techne. These workers do not have equal access to this new scheme of knowledge. Even now no-one speaks of drawing dressmen into collaborative partnerships, but of imposing superior work practices on them. In other words, de-skilling and proletarianization are being glossed as progress, global awareness, and superior taste.

Examining this transformation allows us to understand better social actors in filmmaking that are conventionally ignored, but who represent a critical urban, working population. Neither peasant nor elite, urban skilled workers in new industries have not been well studied in the South Asian context. We also come to appreciate "progress" in commercial filmmaking from a noncelebratory and minority point of view (Caldwell 2006), allowing us to perceive the complexity and costs of Indian filmmaking becoming more entwined into global circuits.

In the pages that follow, I begin by describing the characteristics of the wardrobe department in Hindi film culture, and the place of dressmen within that department. I go on to describe the impact of economic and cultural change in the industry, tracing the particular effects upon dressmen, and how they are positioned, and position themselves, with regard to personnel who advocate for, and make use of, new elements of production culture. 


\section{The Dressman's Line: Responsibilities, Organization and Recruitment}

Although one cannot find any kind of job description for a dressman, dressmen themselves state their responsibilities with a high degree of consistency: to take care of the clothes used in a production from beginning to end of shooting; and to keep costumes safe, cleaned, repaired, and ready for use at any point in the shooting schedule they are needed. Dressman are also called upon to fetch clothes to the set; they visit dresswalas (costume-hire shops from which they collect uniforms and special costumes), laundrymen, jewelers, and tailors responsible for making junior artist, stunt double and stand-in costumes. They acquire standard costume items like belts, t-shirts and so on, and press and prepare the clothes just prior to the shoot. They are also relied upon to obtain costumes at the last minute.

The work of a dressman is well understood in commercial cinema; it goes on in fixed workplaces, on contract terms, and there are institutional bases for corporate worker identity. All dressmen are male, for in the fairly strictly sexually segregated world of Hindi film production, there are no female dressmen. Dressmen include both Hindus and Muslims. Caste-wise the occupation is an open one, meaning that no caste community monopolizes it. Dressmen come mostly from the local state of Maharashtra, or from neighboring Gujarat; others came from as far away as Uttar Pradesh, to the north and east. Most dressmen interviewed belonged to middle or slightly lower castes, although it is quite possible to find dressmen with high caste memberships also. In keeping with their regional origins, dressmen tend to speak Marathi or Gujarati, although they could also speak Hindi (the Hindi film-set lingua franca). They could not, though, speak English, the language that is shared, and to some extent preferred, by filmmaking elites. Dressmen are organized into an occupationallybased worker's association that also includes make-up artists (also all men) and hairdressers (all women). ${ }^{2}$ The association functions like a union in that it annually establishes minimum pay rates, and membership is theoretically a prerequisite for working in the industry. But the dressman's job also has attributes and characteristics that make it more like jobs in the informal sector. Dressman practices span several categories from a western film production unit; the elaboration of roles in, for example, American costume design and management, does not exist in commercial Hindi production. In U. S. cinema, the costume department should ideally be headed by the costume designer, and the department requires a supervisor, or an executive head, to carry out the designer's or the director's wishes. Under the supervisor, costumers of various ranks select, 
fit, store and maintain costumes. ${ }^{3}$ In commercial Hindi cinema, by tradition there is no-one who can be identified as a "wardrobe supervisor" (organizing procurement of costumes and managing wardrobe staff) as opposed to a "costumer," (handling costumes on set), or any other, lesser member of the costume department. Instead there is a plain hierarchy of a head dressman (often referred to both respectfully and fictively as dada, or "grandfather"), and two assistants, with the addition of dressmen hired on a daily basis for crowd and dance scenes. ${ }^{4}$ Dressmen generally do not have a habitual, working relationship with the dress designer: they only take responsibility for costumes made by the designer directly the designer has them delivered to the set.

A degree of uncertainty regarding pay and contracts is part and parcel of a dressman's work. For all the appearance of a contractual relationship between dressmen and producer, the reality is that dressmen cannot, and do not, rely upon a guaranteed wage from any of the production houses they work for. This is largely because of the uncertain nature of film financing (Ganti 2004: 71). Films are shot as money becomes available, and so a dressman cannot expect to work for one company until the film in question is complete. Instead, he commits to anywhere from two to five projects at a time. Although many technicians expect, and get, their pay at the end of each shift, some dressmen do report having to wait for their wages. Spreading one's work around several companies has the added advantage, then, of ensuring a more regular flow of money, for if one producer is behind in payments, another one may not. Spreading the load of work also allows a dressman to build a network of connections that can get him more work in future.

Finally, training and recruitment are unstructured and highly dependent upon patronage and family relationships. Getting a start as a dressman has always depended upon contacts and luck; learning to be a dressman is no more systematic. Typically, the head dressman stays with one film, and directs his assistants to work on the other sets as needed. Going from set to set as an assistant constitutes the sum of training for a young dressman, since there are no objective, professional standards for dressmen, and no broadly agreedupon system of training: "From the beginning I am used to running around and going to ten places. I got into this line by watching [other dressmen]. Slowly, slowly by getting to know people, by saying hi and hello, I got into this line." Gaining experience and building knowledge on the job, under the daily direction of the head dressman, is an example of what Lave and Wenger (1991) call "situated learning," and is highly characteristic of informal work situations. Working as an assistant to a head may occupy from two to three 
years of a dressman's life before he becomes a head dressman; some never reach this goal, and some choose (or are compelled) to work freelance. Almost all my interviewees worked as head dressmen, in charge of a team of dressmen, which has translated into a distinctly middle class, if not necessarily affluent, way of life for them.

Although the dressman's occupation is not part of the informal economy, it would be hard to say that his work carries with it all the associations of a "formal" position. There are no benefits, no guarantees of payment, and the duties are dictated by tradition. The fluidity of work categories is the outcome of a weakly collectivized workforce; there are no fixed boundaries around the responsibilities dressmen have, and no sanctioned ways for dressmen to defend themselves against production houses making additional demands of them, or diverting their responsibilities towards other personnel. What is more, the value of the dressman comes from his ability to resolve some of the quotidian, unpredictable problems of filmmaking that stem from its dispersed and unorganized nature. It is to these problems, and to the dressman's abilities, that I now turn.

\section{Filmmaking Practices and Wardrobe Culture}

Long-established practices in the film industry present their own challenges to, and constraints upon, wardrobe functions. The same uncertain financing that forces dressman to spread their effort over several films means that any given film may take years to complete; shooting continues only as and when money becomes available (Ganti 2004: 71). In response, many stars work on several films at once, giving a few dates out at a time to work on a project (Kabir 2001: 29). In turn, productions must struggle to synchronize dates for lead hero, heroine, and character artists, who are in demand from other production houses at the same time. These two, related problems inevitably cause delays and postponements, sometimes adding up to several months, even years. The shortage of start-up funds, and the fact that stars only sporadically become available to work on a film, mean that costumes are typically made and gathered together just in advance of each shooting schedule.

These experiences are fully in line with Prasad's (1998, 36-51) observations about Hindi filmmaking. Adopting Marx's (1977, 461-63) terminology of "heterogeneous" versus "homogenous" modes of production for filmmaking, Prasad argues that Hindi films are made in the heterogeneous mode, meaning that the components of a film are constructed separately, as part of relatively 
independent traditions, and compiled only at the point of shooting. In contrast, Hollywood films - of the classic era at least-epitomize filmmaking in the homogeneous mode, where the film is composed serially, with a predictable and precise division of labor, according to a pre-determined narrative. To Prasad, the strongest evidence of, and reason for the heterogeneous mode of Hindi filmmaking is the absence - the unimportance, even-of the script. When the entire filmmaking process proceeds from the film's central narrative, a serial process inevitably appears. In Hindi films, though, each component contains its own referents and dynamics that can function independently of any given storyline. Prasad does not mention costume specifically, referring instead to the composition of the music, the fight scenes, the dance scenes and so forth (43), but costuming in Hindi film conforms well to his model in that it is clearly a fragmented process that develops in parallel to the other filmic components. To start with, one costume designer (or what is termed a "dress designer") for a film is very rare; instead, each leading actor and actress retains their own personal designer or menswear store to outfit them in all their films. Of all the indices of celebrity status, having one's own designer is among the most important. When the main stars insist upon their own designers, there is no-one who can claim complete responsibility for costume as a whole, and as a result, dress designer credits often fail to appear "above the line"-in other words in the film's opening credits. Second leads, or "character artists" may occasionally have their own designers; dancers are dressed by a dance dress designer; and junior artist and crowd scenes costumes may be thrown together haphazardly. The only figure who can inject any order or oversight into costume design is the film's director. If the director chooses to create some kind of hierarchy of designers, subject to his control, then he may do so; equally likely, he will adopt a "hands-off" approach, relaying his costume needs through assistants as schedule succeeds schedule.

The de-emphasis of the script has other implications for costume as well. Putting together a comprehensive wardrobe depends upon making a script breakdown, and a script breakdown can only happen with a complete, bound script. A "screenplay" in the Mumbai industry often means no more than a list of scenes with a one-line description; a full script with dialogue is an entirely different matter. A dressman for Shyam Benegal, whose filmmaking roots lie in the independent filmmaking sector, did talk of reading a script several times before filming began with the goal of identifying and tracking costume changes. ${ }^{5}$ Comparable practices are rarely found in the commercial sector. The Bollywood dressman never reads the script beforehand, even assuming 
there is one. Even with an increase in bound scripts for A grade films in recent years (Dwyer 2002; Pfanner 2006), it is far from clear that a systematic breakdown of the script in terms of costume changes as a pre-production practice occurs anywhere but in the independent filmmaking world.

Thus, the dressman is responsible for collecting costumes from a wide variety of sources, often just prior to the shoot for which they are needed. He is then responsible for them until they are needed again, possibly weeks, or even months in the future. If it were not difficult enough to keep track of costumes over such a protracted period of time, actually retrieving a costume for shooting contiguous scenes at discontinuous times is complicated by the conventional system of costume storage used in commercial film. Given the cramped work conditions that prevail on set, the dressmen's workspace may not include a full-sized room for setting out costumes, still less rails for hanging them up. Costumes are kept in trunks, and stowed in a godown (warehouse) at the end of filming. Even in the grandest costume drama, "[I]n one big schedule, 30 to 40 boxes came of belts, caskets, girdles. There were three trunks of jewellery." Dressmen take their responsibility to remember where costumes are, and to disinter them on demand very seriously: "We have to take care of even a needle; we have to put blood on handkerchiefs, we keep it safe in a box. Sometimes, six months later, there will be a shoot, and if the same color is needed it would be difficult to find, so [in this way] we take care of it." Still, given that few productions make a concerted effort to keep or recycle costumes, most directors find it as easy-if not necessarily cheaper-the order costumes anew when a new schedule comes up.

Costume changes in Hindi film act as signifiers of "melodramatic character types," (Mazumdar 2003: 93); they encode emotion (Grimaud 2003); they allow the heroine, in particular, to indulge in masquerade (Dwyer and Patel 2002: 93); and they embody morality (Wilkinson-Weber 2005). But the semiotics of costume are generated and reinforced by costume management practices that force the use of new costumes almost every time a new schedule begins. Consider, for example, that prior to filming, the costume changes from start to finish are simply unknown. As a new schedule approaches, a frenzy of activity ensues as costumes are collected. There are few, if any, opportunities to age or reuse clothes; at worst, the director calls the designer the night before with a string of demands. Instead of a costume narrative that mirrors and expands upon the script, as is widely considered "normative" in American cinema (Gaines and Herzog 1990), there is instead a protean display of costumes. What appears in the finished film is scene following scene of new, 
immaculate costumes - a rich visual fantasy that is, ironically, the artifact of somewhat chaotic organizational practices.

Certainly there are tools associated with continuity maintenance-photographs, continuity books, and so on and so forth-that are used, but none appears to be used systematically. While most dressmen talk of using written notes to assist them in keeping continuity, some do assert quite forcefully that they rely on their memory: "even today I don't write down the continuity... we can get out the dress on the spot." Responsibility for continuity is, in fact, diffused among dressmen, assistant directors, and even actors, whose notorious self-absorption and vanity can actually become useful when deployed to this end. The good actors, say the dressmen, know their own continuity. of one established star, a dressman commented: "[H]e doesn't disturb us much. He knows what to do." Just the same, once costumes reach the point of final disposal in the godown, only the dressman knows what is there.

The job that dressmen take the greatest pride in is finding costumes at the last minute: they know where to find material, they know which tailors will take work at all hours of the night and where to find them. They are regarded by others in the filmmaking team as invaluable in this regard, as real miracle-workers, who can materialize costumes on demand as if by magic:

Once, a new scene came up [on location], so then the dressman was called, that do you think there is in a place like this somewhere we can find this dress? He said "I'll fix it." So he went to a ramshackle little place, bought material from there. He went and got lace from another shop and took all that to a tailor, gave the instructions to the tailor. He got it done in two days.

While unexpected problems occur in filmmaking all over the world, lack of wardrobe pre-planning in the Hindi film industry almost guarantees that there will be recurrent costume emergencies. Over and again, dressmen comments alluded to this issue: "[I]n this industry, work is such that we have to do everything only when the shot is ready." Or, "When today we ask the production department about tomorrow's schedule, they themselves don't know and tell us to come tomorrow early morning and then we'll know the schedule." While independent films "have a schedule" this is "different again from Hindi cinema where you never know what to expect."

In sum, the dressman's value resides in his knack for remembering where those costumes are kept that are absolutely needed to maintain continuity, 
and in his ability to deploy his knowledge, built up through experience, of how and where to get last-minute costumes. The dressman is an exponent of techne; his work depends to a considerable degree upon informal measures and practical principles, as opposed to formal learning. The work he does is intimately connected to his experience, and his seniority (Zuboff 1988: 41). The dressman's knowledge, acquired through experience, is concrete, deriving its character and meaning from the multiple contexts in which he has learned to apply that knowledge. Finally, this knowledge is exclusively the dressman's; no-one else on set knows what he knows. It gives the dressman particular pleasure to return to a shoot with the requested costume, without anyone being able to retrace his steps, or repeat his actions exactly. His knowledge is implicitly part and parcel of doing those things that a dressman does; it is not something that exists as a separate set of instructions that anyone else can follow.

Recent innovations in filmmaking practice are being laid upon this "foundation" which has been well established for the past forty years or so. This is not to say that the dressman's occupation has remained static in this period; in fact, the origins of the trends that are now beginning to unsettle the dressman's traditional knowledge and skill can be traced back to the entry of dress designers into filmmaking.

\section{Dressmen and Costume: Early Years}

The term "dressman" is close to the term "dresser" used in English speaking theater, and perhaps reflects the early influence of theatrical conventions upon filmmaking practice (see Rajadhyaksha 1996a: 398). ${ }^{6}$ The earliest Bombay studios-Kohinoor, Imperial, Ranjit Movietone and Sagar Film Company-were overtly modeled on Hollywood precedents, including a "production assembly line" (Barnouw and Krishnaswamy 1980: 117; Rajadhyaksha 1996a: 403). None, though, seems to have had the complex arrangement of costume shops that were common in Hollywood in its studio era. Instead, heroines and, heroes in particular, contributed their own costumes, or costumes were rented from a dresswala, or an "in-house" tailoring operation handled what was left. In fact, as Prasad (1998: 40) has pointed out, studios were hardly stalwarts of an impersonal manufacturing process, but were "extensions of the joint family," or khandan, where costume workers would have simply comprised "in-house" versions of workshops typically found, and patronized outside the film setting. For this reason, the replacement of the 
studio system with independent investors in the years following World War II and Indian independence (Radhyakhsha 1996a: 409), did not entail a significant shift in costume production arrangement. The oldest dressman I interviewed began work at the tail end of the studio era in 1947, and he said: "Every company had tailor, 1940 to 1950 to 1960. [In] (famed director) Raj Kapoor's time, they used to make clothes, two tailors, two machines, two assistants." The dressman was a logical extension of this team, and he played a prominent and creative role in costume decisions. Indeed, many dressmen used to be tailors, "because they were company dressmen who used to make clothes." In addition, dressmen were (and are) adept at constructing draped and wound garments like saris, dhotis (a man's traditional draped lower garment) and pagdis (turbans), in all their regional variations. The director gave instructions for costumes directly to the dressman, with sketches provided by the art director. A working dressman remarked about his father, a dressman who was one of the first members of the dressmen worker's association: "... when my friends used to ask me what is your father doing then I used to say that he is costume designer and makes the actor wear his clothes. He knew to make pagdi (turban) also dhoti (a man's traditional draped garment)." This description may reflect in part a child's magnification of his father's significance, but it is not too far off the mark.

Film credits either made no mention of costume design, or included scant and elusive references until the 1950s, when the first above-the-line credit to someone who would become a known dress designer, Bhanu Athaiya-credited here as Bhanu Mati-appeared in Guru Dutt's 1957 film, Pyaasa (Wilkinson-Weber 2005, 12). Several female designers followed in her wake, working almost entirely for heroines as their personal designers. These designers worked closely with independent tailors and with dresswalas, getting costumes stitched away from the production houses and sets in tailoring shops and even in their own homes. In that most designers worked explicitly for their actors or actresses, costume was an extension of the star's personal wardrobe and personal service associations. For example, a heroine's tailor might remain constant even as the nominal designer changed (WilkinsonWeber 2004, 17). With the arrival of the dress designer, there began a shift away from dressmen playing a creative role in costume decisions that has only accelerated as economic changes in India have allowed a commercial fashion industry, and new objectives in filmmaking, to emerge. 


\section{Dressmen and Costume: Economic Liberalization and After}

Two things must be borne in mind in order to understand the present condition of filmmaking, and of dressmen within filmmaking: first, the "liberalization" of the Indian economy in the early 1990s, which ushered in greater foreign investment, increased market competition, deregulation and a de-emphasis of the public sector (Khanna 2003: 139; Ganti 2004: 34); and second, changes in government policy toward filmmaking (Khanna 2003:140; Ganti 2004, 50). The first marks both the beginning of new global corporate interests in Indian media, as well as a shift in film subjects and aesthetics. As for the second, in 1998, filmmaking was granted the status of an industry, allowing it certain benefits, including power subsidies, and eligibility for new financing opportunities, that it had not enjoyed previously. The cumulative benefit of the advantages of industry status, with the relaxation of many government constraints upon the operation and flow of capital, specifically, a law passed in 2000 to allow banks and financial institutions to lend to producers has enabled Hindi filmmakers to imagine themselves as potential players in a truly global media market, with all the status and financial rewards that entails.

The significance of these shifts for dressmen comes both in the amount, and intensity of work, and adjustments in the nature of their responsibilities. With the advent of cable and satellite television in the 1990s (Ganti 2004, 35), job opportunities for dressmen have increased, and the numbers of card-carrying members of the association has risen commensurately. Periodically, the association decides to issue a larger number of cards to accommodate the growing number of dressmen. In 2001, reportedly, over a thousand new members were initiated, creating a total of over 3000 card-carrying dressmen. Some dressmen resent what they see as a wholesale glut of the field, making employment less stable for existing members. Others complain that the quality of employee is going down, although, in keeping with the general trend of inflation of educational qualifications, the average level of schooling among dressmen is going up: "Before we were only educated to fifth or sixth level. Now in my union, everyone is SSC pass." Several dressmen reported undercutting of wages in 2002, although this was less of a subject of complaint in interviews three years later, when interviewees reported that wages were stabilizing at a reasonably good rate.

At the same time, the workload has increased as the pace of production has increased, particularly in the past five years. A proliferation of costumes, particularly in dance scenes, is remarked upon by all dressmen with at least twenty or so years' experience. An absolute increase in the number of cos- 
tumes in a film exacerbates the problems of repairing and cleaning costumes between shifts. "In songs, for several people there are up to 90 dress changes. It didn't used to be that way; in songs there were [only] two to three dresses." More and more dressmen report being asked to work for a shift and a half per day, instead of just one. They rarely take any kind of sick leave; in one instance, a dressman was back on the job just days after major surgery.

Second, dressmen report being excluded from conversations with the director and producer as the center of costume gravity moves away from an exclusively cinematic world to a commercial one. "Nowadays we don't see the director's face and directors do not know me. First the director used to call us-'hey Ravi, this is the scene you give the clothes,' now it's just director and designer." Since the early 1990s, dress designers have been more likely to maintain a fashion career alongside their film career. There is now a robust fashion market in India, ranging from off-the-rack clothing to high-end couture. The use of western clothing in commercial Hindi films has accelerated, alongside a lasting change in how western clothes on and off screen communicate about the moral implications of modernity.. Previously the "uniform" of the vamp, western styles have become the stamp of the film heroine's cosmopolitanism, youth and affluence (see Wilkinson-Weber 2005: 11; Dwyer and Patel 2002: 98). At the same time, Indian styles that were the mainstay of dresswalas and dressman-tailors have become less prominent; indeed, Indian styles in film have themselves been subject to a fashion reinterpretation, both drawing from as well as informing made-to-order trousseaux, or off-the-rack garments such as those designed and sold by, among others, designers Abu Jani and Sandeep Khosla, and Nita Lulla. Contemporary designers have incorporated both their own designs, and designer label clothes from international markets into the looks they create for their actors.

These new designers have achieved a degree of media stardom as a result of their multiple engagements in both film and fashion in India (Wilkinson-Weber 2004: 10; 2005: 13). Artists, keenly aware of their cachet as fashion icons, as well as film stars, are more demanding about what they will or will not wear, when formerly, as dressmen insisted, "the director used to say what the heroine would wear." Costume today tends to originate outside and apart from both actors and actresses, imposing its own logic and demands from the fashion industry (Wilkinson-Weber 2005: 13). At the same time, off-the-rack casual and sportswear is so popular and so prevalent that all that an artist needs is a stylist to pull their look together. In the recent film Shabd, for example, no dress designer was credited; instead, several "stylists" were listed in the final credits. 
From being in the first lines of costume production, dressmen have increasingly become little more than employees that fetch the dresses, iron them, and carry them between star and storage trunk. Now, pressure from film elites to remake the wardrobe department even further poses new challenges to the dressman's traditional skill and knowledge.

\section{New Tools for a New Filmmaking}

Until recently, the dressman's job had remained relatively intact from interference by the direction or production team. Admittedly, the dressman's responsibility for making costumes has largely fallen away, but his manner of working, his dependence upon his "tools of the trade" from the way in which costumes were stored, to how they were pressed, to how he would keep continuity, were matters for dressmen alone. As has been noted, costumes are "plugged" into films at the point of shooting, with sometimes the minimum of pre-planning. The dressman in this kind of system has been largely a reactive figure, rather than a proactive one; his value comes in his ability as a quick responder rather than as an organizer or planner.

For much of the past 15 years, the close connection of film costumes with a fashion market has permitted the expression of affluence through costume, as the rapid replacement of costumes throughout a film has tended to create the impression of heroes and heroines with limitless wardrobes. What appears as consumerist freedom, though, is in large part an artifact of the usual way of "doing business" in film, in other words, working out costume needs as schedules demand, not as a pre-production task. Now, a significant fraction of directors, actors, and designers involved in making big-budget, high prestige films argue that in order for Hindi films to be taken seriously in the world, film production must yield to new forms of organization and accountability (see, for example, Dwyer 2002: 179; Ganti 2004: 89; Pfanner 2006: 10). The khandan, or feudal family model of filmmaking, is not likely to die soon; family ownership and control of production houses continues, and acting dynasties with several generations of performers show no sign of fading away. More important is the likely replacement of hierarchical loyalties with impersonal, and ostensibly (if not actually) meritocratic relations among film crews. Older dressmen recall with fondness the paternalistic relations they enjoyed with older stars and producers in the 1950s and 1960s, when the scale of moviemaking was far less than it became at its peak in the 1980s: "If the schedule is for six days for shooting, one day before all techni- 
cians-make up men, dressmen-were called and made to understand the whole movie and their work. This all was explained by the director." One dressman added that the technicians were not alone in losing respect in the industry: "In my father's time there was lot of respect to all. Even the artist will respect the technicians but today in films we-all technicians-don't get respect." What contemporary film elites want is not loyalty, though, but "professionalism," and among the attributes of a professional industry are film departments (like costume) that can achieve the director's and producers' goals without having to rely upon their continual input and control. The difference between the autonomy of professional departments and Prasad's description of independently constructed specialties in a heterogeneous mode would be the common adherence of professional departments to a script, predictability in their functions, and an explicit hierarchy of responsibilities to produce more efficient results.

Almost all the designers I have spoken to agree that the first step in "reforming" the existing system as far as costume is concerned would be to ensure there is one dress designer for a film instead of several. In Karan Johar's 2001 film Kabhi Khushi Kabhie Gham, designer Manish Malhotra was credited as "costume director," meaning he was a kind of "primus inter pares" with fellow designers Rocky S. and Shabina Khan. In other examples, Arjun Bhasin has been the single designer credited on the films of Farhan Akhtar (Dil Chahta Hai and Lakshya), likewise Lovleen Bains (a designer with a background in Merchant-Ivory productions) on The Rising: The Legend of Mangal Pandey and Rang de Basanti, and the redoubtable Bhanu Athaiya continues to take sole credit on the films of Ashutosh Gowarikar (e.g. Lagaan and Swades). Still, though, actors remain attached to their personal designers, and multiple costume credits have by no means disappeared.

A second, and related concern voiced by several designers is the absence of a clearly defined costume supervisor role (however labeled) from set to set. Already, though, it is apparent that informal solutions are being concocted to, in effect, produce a supervisory role. What I am interested in here is, first, the kinds of solutions that can be observed, and second, how these involve-or do not involve-dressmen, who are already the cornerstones of the wardrobe domain. The main solution revolves around assistant directors that specifically take on costume responsibilities, with an emergent possibility of assistants to the costume designer acting as the designer's representative on set. Dressmen largely find themselves excluded from any decision-making role in these arrangements. 


\section{Assistant Directors and Costume Assistants}

Contemporary assistant directors (ADs) are relatively affluent, young, upper middle class persons who are not only more familiar with western filmmaking conventions, but eager to emulate them. They are, moreover, fluent in English, a language that is pushing Hindi aside as a lingua franca among the creative ranks in the industry. A significant minority is female, and to be an assistant director is a role to which young, educated women have been drawn even as the higher level technical specialties, and even directing, remain male domains. Filmmaking has been, and continues to be, a male-dominated industry. There were few roles for women in production until the mid-twentieth century, when film heroines acquired hair stylists, and female costume designers first emerged. The arrival of designers marks one moment of change for the dressman's line, but arguably more important has been the employment of assistant directors since the 1990s, figures who intervene more directly in wardrobe functions.

They come from what Dywer (2000: 91) terms Mumbai's "new middle classes" in that they are entirely at ease with westernized lifestyles, their cultural focus is oriented as much outside as inside India, and they are sympathetic to the new business and entrepreneurial environments that have developed since the early 1990s. They are among the beneficiaries of the new economic regime in India, not simply in the sense of finding work within it, but also as consumers of the plethora of commodities now available and affordable for the affluent, urban middle classes.

The system of ADs is fluid; each production house has its own culture, meaning that arrangements can be very different from one to another. "... sometimes the chief $[A D]$ has to be completely in on the script, sometimes directors don't like the chiefs to be around when script sessions are going on..." Among the ADs, maybe one, often the most junior, is given special responsibility for costume. Alternatively, some companies are using the system prevalent in American filmmaking of first $A D$, second $A D$, and so forth, with clearly distinguishable roles. There is an awareness of these 'production culture' differences among ADs, but each is specific enough that some are surprised to hear of the arrangements that exist in another production. Here, as in other areas of film practice, there are no objective norms for imitation, little training to conform to preset roles and responsibilities in film production, and no structuring of job responsibilities through collective bargaining or contractual agreement.

Not content to leave matters of continuity and planning to the capabilities of head dressmen, many ADs try to introduce more formal organizational tools. 
The systems many ADs use may not be part of a generalized function of keeping order on set; instead they may be personal and idiosyncratic. One AD, who had worked specifically on costume in several productions, related a list of responsibilities that included communicating with the dress designer, and making sure there were sufficient clothes prior to shooting, as well as alternates and extras in case of emergency. These jobs seemed to me to overlap with some dressman duties, but she was clear that these were tasks that she did want to delegate to the dressmen altogether. Evidently, she saw the dressmen as assistants to her, not as personnel in control of their own department. Moreover, in contrast to the dressman's "hands-off" relationship with the designer, such that their interaction begins and ends with the receipt of costumes at the set, the AD seemed to be directly involved in analyzing and breaking down the film:

I give [the dress designer] a one line of the film, of the story of that episode probably, this is what happens, this is the costume, but I would have to make my own charts as to the number of costumes, the continuity and all that, I would have to do that... So based on that one line, I make a chart of the number of people in the film, the number of scenes in a movie, and thereon the number of costume changes based on day/night.

The AD may, in fact, sit in on discussions with the designer, narrating what is needed, helping with a synopsis of the story, and later, he or she applies the pressure to get work done on time. At no point was the dressman included in any capacity other than as a helper.

Some dressmen acknowledged that they looked to ADs for cues on what costumes to provide for which shooting schedule: "She will tell us which shot will have which costumes and the continuity of the shots," but couched this as the AD helping them. Responsibility for continuity is beginning to shift toward the ADs and away from the dressmen and actors, since the ADs will maintain a record of costume changes based on a breakdown that they themselves make. This is probably experienced by dressmen as "helpful" in that it simplifies the more complicated problem of diffused responsibility for continuity, and allows them to simply draw on their own memories to know where costumes are, without having to wonder when they may be needed. Some ADs are now gaining familiarity with software technology that injects new levels of organizational sophistication to filmmaking, and may, in time, eliminate the more spontaneous systems now in place (e.g. Bhatkal 2002: 89). 
I have less data concerning assistants to designers, but from the comments of designers and other personnel on set, it appears that they may duplicate many of the functions described for an AD above. If the second arrangement were to become more prevalent, it would signal a move towards greater conformity to American-style practices, in which the designer is the acknowledged head of the costume department. In other words, the critical figure is the designer, and it remains to be seen the extent to which the designer assumes a larger role in the management of the entire costume process. In the light of this, it is interesting that the dressmen seemed more disturbed by assistants to the designer becoming involved in costume work than ADs. This appears to extend from the conviction that the designer, having traditionally stood aloof from the business of the production house during shooting, had no business now trying to become involved with it: "his job is to make the dress and deliver it; our job is to take care of it." Dressmen perceive a direct threat to livelihood from the designers: one dressman related that he had once arranged for himself and two assistants to work on a film, then one was taken away to accommodate the designer plus his assistant, so that he, the head dressman, ended up with one less assistant. The once the designer's team was in place, "one girl comes with the designer and she'll stick around on set. She'll tell you your job, we have to work just as she likes." While the work of the assistant director in no way affects the number of dressmen employed, or even the traditional distribution of head dressman and assistants, the intrusion of the designer and his or her own assistants has direct and immediate implications for the dressmen. So far, most designers appear content to maintain their customary distance from the set, in part because so many of them have their fashion business to attend to and "don't have time..." Whether things will remain as they are, or whether future elaborations of the designer's role will occur will need to be kept in mind.

What is at stake is not simply the protection of jobs or relations of production on a film set; these processes have implications for film subjects, and film aesthetics. Unstated, but implied in the appeals for pre-planning and efficiency are desires among designers, directors, and producers for the introduction of realism in films. While the escapism, melodrama and resolutely "un"-realistic components of Bollywood are acknowledged as the sources of its appeal, filmmakers are, at the same time, concerned that Hindi films are regarded as slapdash and amateurish. Achieving realism may be, for some, an end in itself; for others, it is the good faith trade-off for global recognition of Hindi filmmaking as a mature industry, particularly among elite Indian and dias- 
poric audiences. Realism entails putting the narrative, the script, in other words, of Prasad's formulation, at the center of operations, and costume best serves the greater goal of realism through being conceived through a careful pre-production process. The conventional pattern of pulling together costumes just prior to the shoot is regarded as hostile to the goal of realism, for two reasons: costumes cannot be aged so as to appear as though they are part of the everyday wardrobe of the character; and costume items are rarely reworn over the course of the film, coordinated with different articles to replicate the way in which a "real" wardrobe might function. An even more difficult demand would be for many copies of a costume, several of which can be aged and modified to form a group that, once arranged sequentially in the finished film, describe a "costume" arc that complements the main story. As illustration, consider the challenges designer Arjun Bhasin must have faced in attempting a form of "costume realism" in the film Dil Chahta Hai (as reported by Kanika Gahlaut 2004: 60):

My effort was to get away from the big disaster of film styling till thenthe matching look. Now, the same pair of trousers will be seen in different scenes, only put together with different elements. Perfectly ironed, brand new outfits are not "cool."

Some years later, Anaita Shroff Adjania found herself in a similar situation costuming Dhoom (Gahlaut 2004, 60):

We have been literally rubbing the clothes in dirt to give them a livedin feel. The more "worn" the look, the more cool it is. This is a far cry from Jeetendra's sparkling all-white ensembles two decades ago.

Realism is here glossed as cool, evidence of the increasing use of colloquial English among dress designers, and the strength of the conviction that realism is the hallmark of a self-aware, contemporary industry. Unspoken is the fact that intentions alone are insufficient to produce the effects that designers desire; in order for them to be achievable and repeatable, the right production structure and culture needs to be in place.

For the dressman, costume realism has other consequences, specifically in that it now entails faithfulness to fashion dictates. When styling, or putting together a character's "look" from ready-made clothing parts, becomes as important a component of wardrobe as designing from scratch, obtaining cos- 
tume is no longer a simple job of taking an order to a tailor. In the eyes of stars, directors, designers and ADs, finding a costume requires the exercise of a critical capacity, trained through gaining familiarity with the language of fashion, and knowledge of the different print and virtual arenas in which it is discussed; in short, it involves the ability to pick an outfit from the boutique, and not the bazaar. To the ADs, directors, designers and so forth, the dressman is a man of limited vision, who cannot understand fashion, has no aesthetic sense, and is a man for whom "it's not within his capacity to understand what I am saying." Lacking the same familiarity with consumer culture that these figures possess, the dressman is a man isolated within his own, entirely different world of tastes, incapable of exercising, or possessing, the distinction (Bourdieu 1984) claimed by his film superiors:

They're [dressmen] very resourceful, but they don't have good taste. I go and shop for those things, buy jewellery from various places. There is a certain amount of education that is sensible, so the dressmen would go and get things like vests and slips, all those kinds of things which he knows exactly what it is. But when I don't know specifically what I want_I'm just hunting — I will buy and find it myself.

Some dressmen openly admit their difficulties: "I don't know anything about color combinations, or where to get certain things. I don't read magazines, I don't know about brands..." In saying this, the dressman colludes in the ADs efforts to set him or herself apart from the dressman. The usual advantages of maleness in a male-dominated industry that have been enjoyed until recently by dressmen are erased by class when educated, English-speaking female ADs can speak the language of fashion more easily with directors and designers, and profess a level of comfort navigating malls and prêt stores that the dressman does not share. The language of designers advocating change is also instructive, in that it seems to presume that the identity of the wardrobe supervisor is likely to be female: ".. the lack is a decent costume assistant on the set who is different from a dressman.... you should have a wardrobe supervisor, so when you have a wardrobe supervisor, she is, she's supposed to be so good at her job to look after these little, little minor alterations and all that...."

In order for episteme to win out over techne in this case, the AD does not have to be a superior dressman-indeed it is inconceivable that they should even attempt such a thing, given the class differentials between the two. 
Instead, they must simply compel dressmen to depend upon them for those components of the wardrobe that the dressmen are ill-equipped to provide, whether that is an analytic approach to the film via the script, or an intimate knowledge of contemporary fashion (see Marglin 1990: 246). So, has the dressman been pushed to the margins of costume production, his job stripped down to a few simple elements where he simply has to follow orders? Although this appears to be a direction that many filmmakers are eager to take, until much more pre-planning can be done in filmmaking, the dressman still has some cards to play. Productions still depend upon their dressmen, for example, to obtain last minute costumes, and success in this endeavor ironically exposes the hollowness of claims about the superior taste of film design sensibilities among film elites. A case in point: dressmen often have to supply substitute items for designer costumes that get lost (for example, in transit to a location shot), damaged, or discolored. If the costume is an elaborate one with beading, embroidering and so on and so forth, nothing but a complete replacement will do. But designer casual wear, like shirts, blouses, t-shirts and so forth, are only special in that their commodity "biography," in the sense employed by Kopytoff (1986: 66), originates from a particular designer or fashion house. The more exclusive brand items still tend to originate outside India; as one old-fashioned designer put it, "they go abroad and buy.....to Singapore, to London." But Mumbai-based designers and menswear stylists enjoy considerable cachet in elite circles, and as I have mentioned previously, stars and designers form close professional relationships in the course of creating the star's wardrobe for a film. The clothes they design, manufacture and sell, whether their destination is a film set or a store front, carry their brand name. Dressmen thoroughly enjoy telling stories of swapping in a lowcost fake for a high-cost original. In this first case, a dressman was prompted by the producer to come up with a cheap alternative, the source of this alternative being left to the dressman's discretion:

One star had Gabbana [a well-known menswear store in Mumbai] t-shirts: he made the choice in first schedule. The cost was Rs. 3000. They wanted more t-shirts. So producer asked dressmen to get it wherever. Who would know if it was Gabbana's or someone else's? We bought them in the bazaar for Rs. 800 each.

In the second instance, the dressman took it upon himself to use his familiar networks to obtain a cheap substitute costume: 
In one movie where designer had stitched a shirt for a star, it got torn in a fight scene. It was military shirt. The director had to hold up the shoot. I went to Goregaon market, got the same material and went to my friend's shop. He stitched it in an hour and I took it back. The shooting continued after lunch break. If that same shirt we would have got from designer, he would charge Rs 4000 . I got it for Rs 1000 , so this is the difference. We have to help the producer and save his money.

All that remains for the dressman in these situations is to persuade the artist, through trickery or lies, that the clothing has the appropriate provenience for a movie star.

In both cases, the dressman subverts the world of distinction presided over by designer, AD, and maybe director, through use of his own forms of knowledge - where to get clothes made - and emphasizing a superior loyalty to the "bottom line," valued by the producer. Filmgoers who follow stars in film media know about their stylists and favorite stores, and to which designer they are currently attached. The "consumption work" (Foster 2005, 11) of the star in the film benefits Gabbana, in the first example, just as the star benefits from his exclusive association with high quality clothes. Only a few parties, the dressman and the producer in this case, know that an unremarkable article of clothing may be "understudying" the real thing, that the designer or stylist's brand is being represented and advanced by something that definitively does not share its prestigious origins. And only the dressman knows for sure where the shirt was obtained, or the costume sewn, that enacts this piece of fakery. Maintaining control of this part of the costume puzzle means that the dressman simultaneously props up and undercuts the powerful synergy of consumerism and cinematic pleasure that has been the hallmark of Hindi filmmaking for the past 15 years.

The designers don't make clothes by themselves. They have some tailor, they must say to him, this is the costume, you make it... The tailor cuts, makes it. In this way it is to be made, it's easy. So what does the designer do? ${ }^{8}$

\section{The Dressman's Line: Talking About Change}

Clearly, no discussion of reform and transformation in the Hindi film industry can proceed on the assumption that this process will not have discrepant 
outcomes for many workers in the industry, or that everyone with a stake in filmmaking has the same goals in mind. The discourses on either side of the barrier separating dressmen from designers, ADs and actors illustrate conflicts over the definition of change in the industry, its causes, and what lies ahead. Designers of the last 15 years, in particular, are ardent supporters of the liberalization of the Indian economy, seeing the rise in their fortunes as fashion designers of a piece with the new wealth of material items to convert into film costume, and the inclusion of India within a global marketplace stressing professionalism, taste, and style. To them, dressmen are potential obstacles to progress,

....they're just concerned with getting the right clothes. They just feel I'm a difficult person. I keep explaining to them that if you feel that I'm introducing a system that only helps you, you use it. I wish they would really just adapt and change.

In saying this, designers reproduce orientalist contructs of modernity versus tradition: they are, as Shohat and Stam $(2003,256)$ put it, "hybrid subjects recreating the other."

The dressmen, in turn, realize that the shifts in costume conventions and the apparel industry threaten to relegate them to the tedious work of ironing, fetching, and carrying. As their skills in tailoring and raping have receded in importance, dressmen have few new skills to take their place. Meanwhile, the class gulf that divides dressmen and their English-speaking superiors makes it difficult for dressmen to break into executive jobs in filmmaking. The dressmen that outwardly complain tend to articulate their critiques in the populist mode: they attribute the changes in costume, and in their work, to a corrosion of culture, not to the workings of capitalism. They grumble about the breaking of ties of obligation between producers, directors, stars and crew, "Today's dressmen are talked about like dhobis (washermen)." These are not complaints about wages; the monetary compensation of being a dressman is not worse, in fact it may even be better than in the past. But it is the loss of respect that galls the dressman most: "Artists used to care that dressman had eaten and drunk: now it's 'eat your food later, first you work, the food isn't going anywhere." The dressmen also dismiss the innovations of fashion in characteristically populist terms: "How can you say yes to vulgarity? Whatever clothes you'll wear, if you want to make money you'll do anything," and discuss the shift toward off the rack costumes in terms of a falling away from 
authentic Indianness: "Today I say designing is zero. See a foreign film, bring a ready-made dress." The validity of the dressmen's critique is subject to debate; but what it tells us about the ruptures in the filmmaking world regarding the future adds considerably depth to current research on commercial Hindi film.

The question remains whether dressmen will able to continue to employ their techne in ways that shore up their value on the set, or whether the epistemization of film practice, in the form of costume pre-planning, oversight by an $\mathrm{AD}$, costume designer or representative, and a script-breakdown, will relegate them to a perpetually subordinate status (Marglin 1990:275).

As some productions and production houses continue the process of filmmaking rationalization, the dressman's job will continue to lose those supervisory elements that had previously put it closer to the costume supervisor position in western filmmaking. His knowledge of the "tiniest" places to get things, his willingness to take costumes to the all-night laundry, or to collect tailoring work from out of the way locations, will still make the dressman indispensable, but only as an assistant, not as a pace-setter in filmmaking.

\section{ACKNOWLEDGMENTS}

Research for this article was funded by the American Institute of Indian Studies and the College of Liberal Arts at Washington State University Vancouver. Many people assisted me in both practical and intellectual ways, including Veena Poonacha and the Research Centre for Women's Studies at SNDT Women's University in Mumbai, Candice Goucher and Amy Wharton of the College of Liberal Arts at WSU Vancouver, Monalisa Sata, Emmanuel Grimaud, Kaushik Bhaumik, Steve Weber, and Rinki Bhattacharya. I am, of course, indebted to the dressmen of the Hindi film industry who agreed to share their time, and their stories, with me. I am also grateful to the editor and anonymous reviewers for Anthropological Quarterly for their comments.

\section{ENDNOTES}

${ }^{1} I$ conducted interviews on-set and off-set with the interview subject and an assistant/translator. I can speak and understand Hindi, but know neither Marathi nor Gujarati. Communication is further complicated by the fact that film workers for whom Hindi is a second language speak a version that is quite different from the Hindi I learned in graduate school. Whenever dressmen were comfortable speaking Hindi, they were asked to do so in order that I might participate in the conversations; in those cases where they were more comfortable speaking Marathi or Gujarati, the translator took a leading role. Monalisa Sata was a skilled translator and assistant, as well as a valued contributor to the analytic progression of the project.

${ }^{2}$ An important function of the female hairdresser is to act, in some ways, as a stand-in wardrobe specialist for the actresses she serves; the dressman is prevented, by rules of inter- 
action that limit close and intimate contact between unrelated men and women-and in particular men and women from different classes and statuses as dressman and actress are- from doing anything much more than bringing the costume to the actress's changing room or trailer. The resilience and implicitness of this convention is brought home in an anecdote told by British actress, Rachel Shelley, in an article about her experiences shooting the Oscar-nominated Lagaan in India in 2001 (Shelley 2002, 2). Playing a nineteenth century British woman required Shelley to wear a succession of elaborately fitted period costumes. To her alarm, she found that no-one was assigned to help her dress. Shelley vents her frustration at what she perceives as ineptness in Indian film production, whereas in fact, the problem was a structural quirk, embedded in popular Hindi filmmaking practice. Indian film heroines are completely accustomed to bringing someone to the set with them who will help them with complex costume fittings, for example, a personal hairdresser (all heroines retain their own, personal hairdresser), her personal costume designer (almost all heroines and heroes have their own costume designer or a friend who buys her clothes), a friend or relative.

${ }^{3}$ Confirmation of these details has come from informants in the American film industry.

${ }^{4}$ The oldest dressman explained that when he began in the business, the head only needed one assistant: "actors never had so many changes in those days; two suits and three to four pants. One pair chappal (sandals) and one pair boots. Actresses would have three to four saris or four dresses. That's it."

${ }^{5}$ Since the 1970s, an independent, low budget filmmaking sector has functioned alongside the commercial one. Termed variously "new wave," or "parallel cinema," it conforms organizationally and thematically to similar independent traditions in other parts of the country. In spite of the apparent opposition between the two cinematic sectors, many actors and some creative personnel (including some designers) have divided their work between the two, and enjoyed success in both (see Rajadhyaksha 1996a; 1996b).

${ }^{6}$ Bombay's theater art-world came into being shortly after 1850 out of Parsi, Gujarati and Marathi theatrical roots (Hansen 2002: 164). Stage technologies were largely European, while drama styles were innovative. Parsi theater companies spread this form of theater outside Bombay, while inside the city, contributors to the institution were drawn from a wide range of castes and classes-reflecting a similar openness in the production side of film.

${ }^{7} \mathrm{SSC}$ pass means that the student completed secondary school education.

${ }^{8}$ While the branding of films and film companies has been remarked upon (Dwyer 2002), there has been, to my knowledge, no detailed study of branding within films, other than to note the popularity of international brand sportswear and so forth in some films (Dwyer and Patel 2002, 89). The substitutability of locally-made 'knock-offs,' which affects both the fashion designer industries as well as the film industry, deserves more attention, not just in the sense that they draw consumers away from brands, or frustrate the integrity of Indian brands, but that they do, in the film context, achieve the goals that brands seek to achieve without having the brand present. In this context, the star is sufficient guarantee of the brand's existence, and validity.

\section{REFERENCES}

Barnouw, E., and K. Subrahmanyam. 1980. Indian film, 2d edition. New York: Oxford University Press.

Bhatkal, S. 2002. The Spirit of Lagaan. Mumbai: Popular Prakashan.

Bourdieu, P. 1984. Distinction: a Social Critique of the Judgement of Taste. Cambridge, Mass.: Harvard University Press. 
Bruzzi, S. 1997. Undressing Cinema: Clothing and Identity in the Movies. London: New York.

Caldwell, J. 2006. "Cultural Studies of Media Production: Critical Industrial Practices," in Questions of Method in Cultural Studies. Edited by J. a. M. W. Schwoch, pp. 109-153. Malden, MA: Blackwell Publishing.

Ciecko, A. T. 2006. Contemporary Asian Cinema: Popular Culture in a Global Frame. Asian cinema series. Oxford: Berg.

Dwyer, Rachel. 2002. Yash Chopra, World Directors Series; London: British Film Institute,

Dwyer, R., and D. Patel. 2002. Cinema India: the Visual Culture of Hindi Film. New Brunswick, New Jersey: Rutgers University Press.

Foster, R. J. 2005. "Commodity Futures: Labour, Love and Value." Anthropology Today 21:812.

Gahlaut, K. 2004. "Style it like Bollywood." India Today, pp. 60.

Gaines, J., and C. Herzog. 1990. Fabrications: Costume and the Female Body. AFI film readers; New York: Routledge.

Ganti, Tejaswini. 2004 .Bollywood: A Guidebook to Popular Hindi Cinema, Routledge Film Guidebooks;. New York: London,

Grimaud, Emmanuel. 2003. Bollywood Film Studio, Ou, Comment Les Films Se Font À Bombay, Collection Monde Indien.; Sciences Sociales 15e-20e Siècle;. Paris: CNRS.

Hansen, Kathryn. 2002. "A Different Desire, a Different Femininity: Theatrical Transvestism in the Parsi, Gujarati, and Marathi Theatres, 1850-1940." In Queering India: Same-Sex Love and Eroticism in Indian Culture and Society, edited by Ruth Vanita, 163-80. New York: Routledge,

Jain, A. 2006. "Hollywood Films look to India for their Action The Financial Times, March 7, pp. 10. London.

Kabir, Nasreen. 2001. Bollywood: The Indian Cinema Story. London: Channel 4 Books,

Kopytoff, I. 1986. "The Cultural Biography of Things: Commoditization as Process." In The Social Life of Things. Edited by A. Appadurai, pp. 64-94. New York: Cambridge University Press.

Lave, Jean, and Etienne Wenger. 1991. Situated Learning: Legitimate Peripheral Participation, Learning in Doing;. Cambridge [England]: New York.

Liechty, M. 2002. Suitably Modern: Making Middle Class Culture in a New Consumer Society. Princeton, N.J.: Woodstock.

Marglin, Stephen A. 1990. "Losing Touch: The Cultural Conditions of Worker Accommodation and Resistance." In Dominating Knowledge: Development, Culture, and Resistance, edited by Frédérique Apffel-Marglin and Stephen A Marglin, 217 - 82. New York Oxford University.

Marx, K. F. B. 1977. Capital: a Critique of Political Economy. New York: Vintage Books.

Mazumdar, N. 2003. "Doubling, Stardom, and Melodrama in Indian Cinema: The impossible role of Nargis." Postscript 22:89-103.

Pfanner, Eric. 2006. "India's New Cinema Has a Global Script." International Herald Tribune, May 22, 10.

Prasad, M. Madhava. 1998. Ideology of the Hindi Film: A Historical Construction. Delhi: New York.

Rajadhyaksha, Ashish. 1996a. "India: Filming the Nation "In The Oxford History of World Cinema, edited by Geoffrey Nowell-Smith, 678-89. New York: Oxford University Press, 
1996b. "Indian Cinema: Origins to Independence "In The Oxford History of World Cinema, edited by Geoffrey Nowell-Smith, 398-408. New York: Oxford University.

Sengupta, S. 2005. "Reflected Readings in Available Light: Cameramen in the Shadows of Hindi Cinema." In Bollyworld: An Introduction to Popular Hindi Cinema. Edited by R. a. A. J. S. Kaur, pp. 118-142. New Delhi: Sage.

Shelley, Rachel. 2001. "Love in a Hot Climate." The Guardian May 11, 2.

Shohat, Ella, and Robert Stam. 2003. Multiculturalism, Postcoloniality, and Transnational Media, Rutgers Depth of Field Series. New Brunswick, NJ: Rutgers University Press.

Stacey, J. 1994. Star Gazing: Hollywood Cinema and Female Spectatorship. London: New York.

Street, S. 2001. Costume and Cinema: Dress Codes in Popular Film. New York: Wallflower Books.

Virdi, J. 2003. The Cinematic Imagination: Indian Popular Films as Social History. New Brunswick, N.J.: London: Rutgers University Press.

Wilkinson-Weber, Clare. 2004. "Behind the Seams: Designers and Tailors in Popular Hindi Cinema." Visual anthropology review: journal of the Society for Visual Anthropology 20, no. 2: 3-21.

2005. "Tailoring Expectations: How Film Costume Becomes the Audience's Clothes." South Asian Popular Culture 3: 135-59.

Zuboff, S. 1988. In the Age of the Smart Machine: the Future of Work and Power. New York: Basic Books. 